\section{BRAZIULIAN JOURNAL}

OF MEDICAL AND BIOLOGICAL RESFARCH

www.bjournal.com.br
ISSN 0100-879X

Volume 43 (3) 182-267 March 2011

BIOMEDICAL SCIENCES

AND

CLINICAL INVESTIGATION

Braz J Med Biol Res, March 2011, Volume 44(3) 240-244

doi: 10.1590/S0100-879X2011007500010

Variants of transcription factor 7-like 2 (TCF7L2) gene and incident glucose intolerance in Japanese-Brazilians

L.F. Franco, F. Crispim, A.C. Pereira, Japanese-Brazilian Diabetes Study Group and R.S. Moisés

The Brazilian Journal of Medical and Biological Research is partially financed by

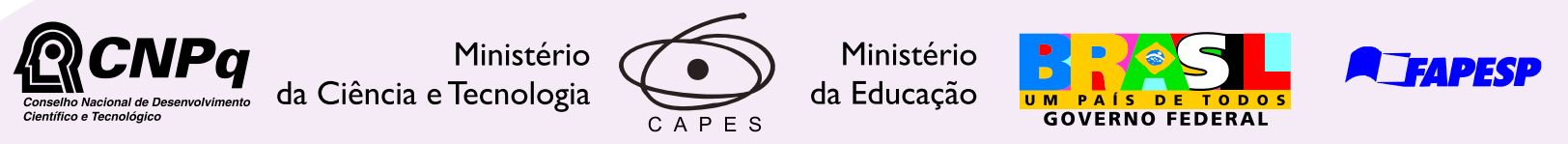

Institutional Sponsors
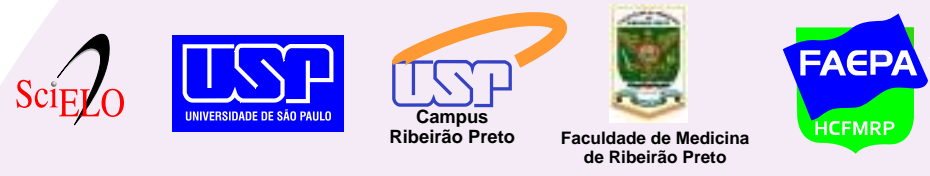

de Ribeirão Pretic

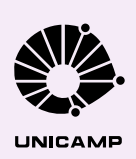

$\oplus$ SHIMADZU

GE Healthcare
Hotsite of proteomics metabolomics developped by:

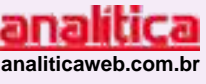

Thermo
SCIENTIFIC 


\title{
Variants of transcription factor 7-like 2 (TCF7L2) gene and incident glucose intolerance in Japanese-Brazilians
}

\author{
L.F. Franco ${ }^{1}$, F. Crispim ${ }^{1}$, A.C. Pereira ${ }^{2}$, \\ Japanese-Brazilian Diabetes Study Group and R.S. Moisés ${ }^{1}$ \\ ${ }^{1}$ Disciplina de Endocrinologia, Escola Paulista de Medicina, \\ Universidade Federal de São Paulo, São Paulo, SP, Brasil \\ ${ }^{2}$ Instituto do Coração, Universidade de São Paulo, São Paulo, SP, Brasil
}

\begin{abstract}
Common variants of the transcription factor 7-like 2 (TCF7L2) gene have been found to be associated with type 2 diabetes in different ethnic groups. The Japanese-Brazilian population has one of the highest prevalence rates of diabetes. Therefore, the aim of the present study was to assess whether two single-nucleotide polymorphisms (SNPs) of TCF7L2, rs7903146 and rs12255372, could predict the development of glucose intolerance in Japanese-Brazilians. In a population-based 7-year prospective study, we genotyped 222 individuals (72 males and 150 females, aged $56.2 \pm 10.5$ years) with normal glucose tolerance at baseline. In the study population, we found that the minor allele frequency was 0.05 for SNP rs7903146 and 0.03 for SNP rs12255372. No significant allele or genotype association with glucose intolerance incidence was found for either SNP. Haplotypes were constructed with these two SNPs and three haplotypes were defined: CG (frequency: 0.94), TT (frequency $=0.027$ ) and TG (frequency $=0.026$ ). None of the haplotypes provided evidence for association with the incidence of glucose intolerance. Despite no associations between incidence of glucose intolerance and SNPs of the TCF7L2 gene in Japanese-Brazilians, we found that carriers of the CT genotype for rs7903146 had significantly lower insulin levels $2 \mathrm{~h}$ after a 75-g glucose load than carriers of the CC genotype. In conclusion, in Japanese-Brazilians, a population with a high prevalence of type 2 diabetes, common TCF7L2 variants did not make major contributions to the incidence of glucose tolerance abnormalities.
\end{abstract}

Key words: TCF7L2; Glucose intolerance; Japanese-Brazilians

\section{Introduction}

Population groups with defined characteristics have been studied to assess the role of environmental and genetic factors in the etiology of non-communicable diseases such as diabetes mellitus. A previous study on JapaneseBrazilians showed that $22.6 \%$ of this population had diabetes in the first phase of the study. In the second phase of the study, 7 years later, this prevalence had increased to $36.1 \%$, being one of the highest worldwide (1). This situation could be reflecting the strong genetic susceptibility of this population associated with an unfavorable environment.

It is well known that type 2 diabetes has a strong genetic background. At present, it is not well understood how many genes are involved and what their relative contributions are to the development of diabetes mellitus. In 2006, Grant et al. (2) identified a microsatellite marker (DG10S478) in the transcription factor 7 -like 2 gene (TCF7L2) that showed strong association with type 2 diabetes in Icelandic individuals, with replication in Danish and US cohorts. The single-nucleotide polymorphisms (SNPs) with the strongest correlation with DG10S478 were rs7903146, rs12255372, rs7901695, rs11196205, and rs7895340. After this initial finding many other studies have found consistent associations between TCF7L2 variants and type 2 diabetes in populations of different ethnic groups (3-10).

The TCF7L2 gene product is a transcription factor involved in the Wnt signaling pathway. This pathway is considered to be critical for multiple developmental and growth-regulating processes of the cell (11). Reduced insulin secretion might be the essential component by which TCF7L2 polymorphisms increase the risk of diabe-

Correspondence: R.S. Moisés, Disciplina de Endocrinologia, Escola Paulista de Medicina, UNIFESP, Rua Botucatu, 740, $2^{\circ}$ andar, 04034-970 São Paulo, SP, Brasil. Fax: +55-11-5579-6636. E-mail: rmoises@unifesp.br

Received September 11, 2010. Accepted January 3, 2011. Available online January 28, 2011. Published March 7, 2011. 
tes. However, the precise molecular mechanism(s) remain to be elucidated. Since in a previous study Yi et al. (12) described the role of TCF7L2 in the regulation of the proglucagon gene, which encodes glucagon, glucagon-like peptide 1 (GLP-1) and GLP-2, it had been suggested that the association with type 2 diabetes may involve an impaired incretin effect (2). Despite the role of TCF7L2 in the transcriptional regulation of the proglucagon gene, plasma GLP-1 concentrations during oral glucose tolerance or mixed meal tests were not significantly influenced by the TCF7L2 polymorphisms $(13,14)$. Therefore, the lower incretin-mediated insulin response seems to be the result of an under-responsiveness of pancreatic $\beta$-cells rather than a reduction in GLP-1 secretion $(14,15)$.

The aim of the present study was to assess whether two SNPs of the TCF7L2 gene, rs7903146 and rs12255372, could predict the development of glucose intolerance in a Japanese-Brazilian population.

\section{Material and Methods}

The study population consisted of individuals recruited from the Japanese-Brazilian Diabetes Study Group, a survey designed to estimate the prevalence and incidence of diabetes and associated diseases in a Japanese-Brazilian population living in Bauru, São Paulo State, Brazil. Details on the selection and recruitment of the sample population have been previously reported (1). Briefly, the first phase of the study involved all individuals aged $40-79$ years from the first generation (Issei) and a random sample (one third plus $20 \%$ ) of those from the second generation (Nisei) from the same age group. A total of 647 individuals were examined and submitted to an oral glucose tolerance test (OGTT). In the second phase of the study, seven years later, the glucose tolerance status of 394 subjects was reexamined (follow-up rate: $61 \%$ ). For the present study, we enrolled 222 individuals ( 72 males and 150 females aged 56.2 \pm 10.5 years) with normal glucose tolerance in the first phase of the study and suitable DNA samples.

The glucose tolerance status was based on the 1999 WHO criteria (16). Plasma glucose was determined by the glucose-oxidase method. Insulin and proinsulin were determined by a monoclonal antibody-based immunofluorimetric assay $(17,18)$. Homeostasis model assessment (HOMA) was used to assess $\beta$-cell function (HOMA- $\beta$ ) and insulin resistance (HOMA-IR) (19).

\section{Genotyping TCF7L2 rs7903146 and rs12255372}

Blood samples were obtained from each subject and genomic DNA was extracted from peripheral blood leukocytes using a commercial kit (Puregene DNA Isolation Kit, Gentra System, USA). Both SNPs were genotyped using TaqMan SNP Genotyping Assays (Applied Byosystem, USA) according to manufacturer instructions. The genotyping success rate was $96.4 \%$ for rs 7903146 and $92.8 \%$ for rs 12255372 . The quality control for these assays was assessed by direct sequencing of 10 samples with different genotypes. The concordance observed between genotyping assays was $100 \%$.

This study was approved by the Ethics Committee of Escola Paulista de Medicina, Universidade Federal de São Paulo, and all subjects gave written informed consent to participate.

\section{Statistical analysis}

All statistical analyses were performed using the Stata version 9.1 software (Statacorp, USA). Continuous data are reported as means $\pm S D$ unless otherwise specified. Variables with skewed distributions were log transformed to satisfy assumptions of normality and back-transformed values are shown. The Student $t$-test, $\mathrm{X}^{2}$ or Fisher test was used as appropriate. Haplotype frequency, Hardy-Weinberg equilibrium, and linkage disequilibrium statistics were obtained using the Haploview software.

\section{Results}

The comparison of subjects' baseline characteristics showed a worse metabolic profile among those who progressed to glucose intolerance at the 7-year follow-up (Table 1). Subjects who continued to have normal glucose tolerance had lower mean values of body mass index, waist circumference, fasting plasma glucose concentrations, and HOMA-IR.

Of the 214 individuals genotyped for the rs7903146 variant, 191 (89\%) had the CC genotype and 23 (11\%) had the CT genotype. Of the 206 individuals genotyped for the rs12255372 variant, 192 (93\%) had the GG genotype and $14(7 \%)$ had the GT genotype. The genotypic distribution of both SNPs was in Hardy-Weinberg equilibrium. The minor allele frequency of SNP rs7903146 was 0.05 and

Table 1. Baseline characteristics of individuals who continued to have normal glucose tolerance (NGT) and individuals who progressed to glucose intolerance.

\begin{tabular}{llc}
\hline Characteristics & \multicolumn{1}{c}{$\begin{array}{c}\text { NGT } \\
(\mathrm{N}=50)\end{array}$} & $\begin{array}{c}\text { Glucose intolerance } \\
(\mathrm{N}=172)\end{array}$ \\
\hline Age (years) & $58.4 \pm 11.0$ & $55.5 \pm 10.5$ \\
Body mass index $\left(\mathrm{kg} / \mathrm{m}^{2}\right)$ & $22.7 \pm 3.0$ & $24.6 \pm 3.6^{*}$ \\
Waist circumference $(\mathrm{cm})$ & $79.4 \pm 11.0$ & $86.0 \pm 9.0^{*}$ \\
Fasting plasma glucose $(\mathrm{mg} / \mathrm{dL})$ & $87.8 \pm 7.3$ & $92.4 \pm 8.6^{*}$ \\
HOMA- $\beta$ & $47.9 \pm 34$ & $68.7 \pm 97.5$ \\
HOMA-IR & $0.67 \pm 0.8$ & $1.18 \pm 1.8^{*}$ \\
\hline
\end{tabular}

Data are reported as means \pm SD. HOMA- $\beta=$ homeostasis model assessment of $\beta$-cell function; HOMA-IR $=$ homeostasis model assessment of insulin resistance. ${ }^{*} P<0.05$ compared to individuals with normal glucose tolerance (Student $t$-test). 
that of SNP rs12255372 was 0.03. The genotype and allele frequencies of both SNPs of subjects who continued to have normal glucose tolerance and the ones who progressed to glucose intolerance are shown in Table 2. No significant allele or genotype association was found with the incidence of glucose intolerance. Linkage disequilibrium analysis showed that the alleles of the two polymorphisms were moderately associated ( $D^{\prime}=$ 0.76). Haplotypes were constructed with these SNPs and three haplotypes were defined: CG (frequency $=0.94$ ), TT (frequency $=0.027$ ) and TG (frequency $=0.026$ ). None of the haplotypes provided evidence for an association with the incidence of glucose intolerance (Table 3).

The relationship of $\mathrm{rs7903146}$ and rs12255372 with $\beta$-cell function measures was assessed at baseline. Carriers of the CT genotype for rs7903146 had lower 2-h insulin levels after the OGTT than carriers of the CC genotype $(\mathrm{CC}=138.30 \pm 133.73 \mathrm{pmol} / \mathrm{L}, \mathrm{CT}=$ $81.40 \pm 78.70 \mathrm{pmol} / \mathrm{L}, \mathrm{P}=0.02)$. Also, a trend towards lower 2-h insulin levels was observed in GT carriers of rs12255372 (GG $=130.40 \pm$ $125.90 \mathrm{pmol} / \mathrm{L}, \mathrm{GT}=77.00 \pm 75.44 \mathrm{pmol} / \mathrm{L}, \mathrm{P}$ $=0.07$; Table 4).

\section{Discussion}

In this study, we tested for associations between incidence of glucose intolerance and SNPs of the TCF7L2 gene in a cohort of Japanese-Brazilians. Although TCF7L2 variants have been consistently associated with an increased risk for type 2 diabetes in diverse populations (3-10), the present study showed that the presence of SNPs rs7903146 square test). and rs12255372 did not predict glucose intolerance in Japanese-Brazilians. Guo et al. (20), in a large study group of Pima Indians, also did not find an association between TCF7L2 polymorphisms and type 2 diabetes. Also, Florez et al. (21) reported associations of the TCF7L2 gene with increased risk of developing diabetes in the Diabetes Pre-

Table 2. Genotype and allele frequencies of single-nucleotide polymorphisms (SNPs) rs7903146 and rs12255372 of subjects who remained with normal glucose tolerance (NGT) and those who progressed to glucose intolerance.

\begin{tabular}{lcccc}
\hline SNP & \multicolumn{2}{c}{ Genotype } & \multicolumn{2}{c}{ Allele } \\
\hline rs7903146 & CC & CT & C & T \\
NGT & $44(89.8)$ & $5(10.2)$ & $93(94.9)$ & $5(5.1)$ \\
Glucose intolerance & $147(89.1)$ & $18(10.9)$ & $312(94.5)$ & $18(5.5)$ \\
& & & & \\
rs12255372 & GG & GT & G & T \\
NGT & $44(93.6)$ & $3(6.38)$ & $91(96.8)$ & $3(3.2)$ \\
Glucose intolerance & $148(93.1)$ & $11(6.92)$ & $307(96.5)$ & $11(3.5)$ \\
\hline
\end{tabular}

Data are reported as number $(\mathrm{N})$ with percent in parentheses. All $\mathrm{P}$ values were $>0.05$ when comparing NGT and glucose intolerance (Fisher exact test).

Table 3. Haplotype frequencies of subjects who remained with normal glucose tolerance (NGT) and those who progressed to glucose intolerance.

\begin{tabular}{lcc}
\hline Haplotype rs7903146, rs12255372 & Glucose intolerance & NGT \\
\hline CG & 0.940 & 0.939 \\
TT & 0.027 & 0.025 \\
TG & 0.026 & 0.026 \\
\hline
\end{tabular}

All $P$ values were $>0.05$ when comparing NGT and glucose intolerance (chi-

Table 4. Baseline characteristics by genotypes for the TCF7L2 single-nucleotide polymorphisms of the subjects studied.

\begin{tabular}{|c|c|c|c|c|}
\hline \multirow[t]{2}{*}{ Characteristics } & \multicolumn{2}{|c|}{ rs7903146 } & \multicolumn{2}{|c|}{ rs12255372 } \\
\hline & $\mathrm{CC}(\mathrm{N}=191)$ & $\mathrm{CT}(\mathrm{N}=23)$ & $G G(N=192)$ & GT $(N=14)$ \\
\hline Age (years) & $56.4 \pm 9.9$ & $57.4 \pm 10.5$ & $56.5 \pm 9.9$ & $57.4 \pm 11.2$ \\
\hline Body mass index $\left(\mathrm{kg} / \mathrm{m}^{2}\right)$ & $24.3 \pm 3.6$ & $23.5 \pm 3.2$ & $24.3 \pm 3.7$ & $23.1 \pm 2.5$ \\
\hline Fasting glucose (mg/dL) & $91.8 \pm 8.5$ & $88.8 \pm 9.4$ & $92.0 \pm 8.4$ & $88.5 \pm 9.8$ \\
\hline 2-h glucose (mg/dL) & $100.8 \pm 20.8$ & $92.1 \pm 23.3$ & $99.1 \pm 21.2$ & $96.2 \pm 26.3$ \\
\hline Fasting insulin (pmol/L) & $15.8 \pm 13.1$ & $10.0 \pm 8.0$ & $14.4 \pm 11.8$ & $8.1 \pm 6.3$ \\
\hline 2-h insulin (pmol/L) & $138.3 \pm 133.7$ & $81.4 \pm 78.7^{*}$ & $130.4 \pm 125.9$ & $77.0 \pm 75.4$ \\
\hline Fasting proinsulin (pmol/L) & $3.3 \pm 2.2$ & $2.9 \pm 2.0$ & $3.4 \pm 2.3$ & $2.5 \pm 1.8$ \\
\hline 2-h proinsulin (pmol/L) & $13.1 \pm 10.6$ & $12.6 \pm 10.4$ & $13.1 \pm 10.6$ & $12.2 \pm 10.2$ \\
\hline
\end{tabular}

Data are reported as means $\pm \mathrm{SD}$. ${ }^{*} \mathrm{P}<0.05, \mathrm{CT}$ compared to CC (Student $t$-test). 
vention Program cohort. However, in the Asian subgroup analysis there were no associations of the polymorphisms with type 2 diabetes. Our findings suggest that this particular population has a different set of genetic risk factors for type 2 diabetes. In this scenario, this population may be used as a resource to identify new genetic risk factors for this complex phenotype.

The underlying mechanism by which intronic variations of the TCF7L2 gene without obvious function in gene regulation contribute to the development of type 2 diabetes in most populations remains to be elucidated. One possibility is that the association with type 2 diabetes reflects a linkage disequilibrium with more distant functional alleles. A difference in linkage disequilibrium pattern with a putative functional variant in Japanese-Brazilians may be an explanation for the lack of association between the SNPs studied and the incidence of glucose intolerance in this population. Similarly, Chang et al. (22) studying a Han Chinese population, found no associations between SNPs rs7903146 and rs12255372 and type 2 diabetes, but identified a novel risk-conferring SNP, rs290487.

The frequencies of minor alleles of the two SNPs, which are the high-risk alleles for diabetes in most populations, were very low in this Japanese-Brazilian population. Similarly, Horikoshi et al. (10) and Chang et al. (22), studying samples of Japanese and Chinese populations, found that the minor allele frequencies of these SNPs were lower than those previously reported for Caucasians, meaning that studies on Asians have less power. In fact, one limitation of the present study was the relatively small statistical power derived from both low minor allele frequency and small sample size. Nonetheless, if one analyzes the point estimate of risk (in our case the presence of a T allele was associated with an RR of only $1.01,95 \% \mathrm{Cl}=0.81-1.28$ ) it is interesting to observe that there was no tendency of association in our sample. Indeed, in most studies able to show an association between the T allele of this SNP and the prevalence or incidence of type 2 diabetes, the presence of the risk allele was associated with a $30 \%$ increased risk. This suggests that other factors are responsible for not detecting an association than only a reduced statistical

\section{References}

1. Gimeno SG, Ferreira SR, Franco LJ, Hirai AT, Matsumura L, Moises RS. Prevalence and 7-year incidence of type II diabetes mellitus in a Japanese-Brazilian population: an alarming public health problem. Diabetologia 2002; 45: 1635-1638.

2. Grant SF, Thorleifsson G, Reynisdottir I, Benediktsson R, Manolescu A, Sainz J, et al. Variant of transcription factor 7-like 2 (TCF7L2) gene confers risk of type 2 diabetes. Nat Genet 2006; 38: 320-323.

3. Groves CJ, Zeggini E, Minton J, Frayling TM, Weedon MN, Rayner NW, et al. Association analysis of 6,736 U.K. sub- power in the present study.

Despite the lack of association between incidence of glucose intolerance and SNPs of TCF7L2 gene in Japanese-Brazilians, we found that carriers of the CT genotype for rs7903146 had lower insulin levels at $2 \mathrm{~h}$ after a $75-\mathrm{g}$ glucose load than carriers of the CC genotype. Saxena et al. (6), studying non-diabetic individuals, found a significant reduction in the area under the curve for insulin during the OGTT in homozygous carriers of the rs7903146 risk allele. Also, Pilgaard et al. (13) found in young healthy men a reduced $24-h$ insulin concentration and a reduced insulin secretion during a mixed meal in carriers of the T allele for rs7903146. These findings indicate that TCF7L2 variants may increase diabetes risk by reduced insulin secretion rather than by reduced insulin action.

In summary, in Japanese-Brazilians, a population with a high prevalence of type 2 diabetes, common TCF7L2 variants did not make a major contribution to the incidence of glucose tolerance abnormalities.

\section{Acknowledgments}

We wish to thank members of the Japanese-Brazilian Diabetes Study Group: Alcides Hirai, MD; Amélia T. Hirai, MD; Helena Harima, MD; Katsumi Osiro, MD; Magid lunes, MD, PhD (in memoriam); Mário Kikuchi, PhD; Sandra R.G. Ferreira, MD, PhD; Suely G.A. Gimeno, PhD (Preventive Medicine Department, Federal University of São Paulo, Brazil); Laércio J. Franco, MD, PhD (Preventive Medicine Department, Faculty of Medicine of Ribeirão Preto, São Paulo University, Brazil); Luiza Matsumura MD, PhD; Regina S. Moisés, MD, PhD (Internal Medicine Department, Federal University of São Paulo, Brazil); Marly A. Cardoso, PhD (Nutrition Department, Faculty of Public Health, São Paulo University, Brazil); Newton de Barros Jr., MD, PhD (Surgery Department, Federal University of São Paulo, Brazil), Nilce Tomita, PhD (Faculty of Odontology of Bauru, São Paulo University, Brazil); Katsunori Wakisaka (Japanese-Brazilian Study Center, Brazil), and Rita Chaim (Nutrition Department, Sagrado Coração de Jesus University, Bauru, Brazil). jects provides replication and confirms TCF7L2 as a type 2 diabetes susceptibility gene with a substantial effect on individual risk. Diabetes 2006; 55: 2640-2644.

4. Scott LJ, Bonnycastle LL, Willer CJ, Sprau AG, Jackson AU, Narisu N, et al. Association of transcription factor 7-like 2 (TCF7L2) variants with type 2 diabetes in a Finnish sample. Diabetes 2006; 55: 2649-2653.

5. Zhang C, Qi L, Hunter DJ, Meigs JB, Manson JE, van Dam $\mathrm{RM}$, et al. Variant of transcription factor 7-like 2 (TCF7L2) gene and the risk of type 2 diabetes in large cohorts of U.S. women and men. Diabetes 2006; 55: 2645-2648. 
6. Saxena R, Gianniny L, Burtt NP, Lyssenko V, Giuducci C, Sjogren $\mathrm{M}$, et al. Common single nucleotide polymorphisms in TCF7L2 are reproducibly associated with type 2 diabetes and reduce the insulin response to glucose in nondiabetic individuals. Diabetes 2006; 55: 2890-2895.

7. Damcott CM, Pollin TI, Reinhart LJ, Ott SH, Shen H, Silver $\mathrm{KD}$, et al. Polymorphisms in the transcription factor 7-like 2 (TCF7L2) gene are associated with type 2 diabetes in the Amish: replication and evidence for a role in both insulin secretion and insulin resistance. Diabetes 2006; 55: 26542659.

8. Cauchi S, Meyre D, Choquet H, Dina C, Born C, Marre M, et al. $T C F 7 L 2$ variation predicts hyperglycemia incidence in a French general population: the data from an epidemiological study on the Insulin Resistance Syndrome (DESIR) study. Diabetes 2006; 55: 3189-3192.

9. Chandak GR, Janipalli CS, Bhaskar S, Kulkarni SR, Mohankrishna P, Hattersley AT, et al. Common variants in the TCF7L2 gene are strongly associated with type 2 diabetes mellitus in the Indian population. Diabetologia 2007; 50: 6367.

10. Horikoshi M, Hara K, Ito C, Nagai R, Froguel P, Kadowaki T. A genetic variation of the transcription factor 7 -like 2 gene is associated with risk of type 2 diabetes in the Japanese population. Diabetologia 2007; 50: 747-751.

11. Prunier C, Hocevar BA, Howe PH. Wnt signaling: physiology and pathology. Growth Factors 2004; 22: 141-150.

12. Yi F, Brubaker PL, Jin T. TCF-4 mediates cell type-specific regulation of proglucagon gene expression by beta-catenin and glycogen synthase kinase-3beta. J Biol Chem 2005; 280: 1457-1464.

13. Pilgaard K, Jensen CB, Schou JH, Lyssenko V, Wegner L, Brons C, et al. The T allele of rs7903146 TCF7L2 is associated with impaired insulinotropic action of incretin hormones, reduced $24 \mathrm{~h}$ profiles of plasma insulin and glucagon, and increased hepatic glucose production in young healthy men. Diabetologia 2009; 52: 1298-1307.

14. Schafer SA, Tschritter O, Machicao F, Thamer C, Stefan N,
Gallwitz B, et al. Impaired glucagon-like peptide-1-induced insulin secretion in carriers of transcription factor 7-like 2 (TCF7L2) gene polymorphisms. Diabetologia 2007; 50: 2443-2450.

15. Nauck MA, Meier JJ. The enteroinsular axis may mediate the diabetogenic effects of TCF7L2 polymorphisms. Diabetologia 2007; 50: 2413-2416.

16. World Health Organization. Definition, diagnosis and classification of diabetes mellitus and its complications. Report of a WHO consultation. Geneva: WHO; 1999.

17. Vieira JG, Nishida SK, Lombardi MT, Tachibana TT, Obara $\mathrm{LH}$, Dalbosco IS, et al. Comparison of the determination of insulin by a monoclonal antibody-based immunofluorometric assay and by radioimmunoassay. Braz J Med Biol Res 1995; 28: 537-543.

18. Dalbosco IS, Vieria JG, Nishida SK, Lombardi MT, Moises RC, Coifman R, et al. A specific and highly sensitive timeresolved fluoroimmunoassay for human proinsulin. Braz $J$ Med Biol Res 1996; 29: 193-199.

19. Matthews DR, Hosker JP, Rudenski AS, Naylor BA, Treacher DF, Turner RC. Homeostasis model assessment: insulin resistance and beta-cell function from fasting plasma glucose and insulin concentrations in man. Diabetologia 1985; 28 : 412-419.

20. Guo T, Hanson RL, Traurig M, Muller YL, Ma L, Mack J, et al. TCF7L2 is not a major susceptibility gene for type 2 diabetes in Pima Indians: analysis of 3,501 individuals. Diabetes 2007; 56: 3082-3088.

21. Florez JC, Jablonski KA, Bayley N, Pollin TI, de Bakker PI, Shuldiner AR, et al. TCF7L2 polymorphisms and progression to diabetes in the Diabetes Prevention Program. N Engl J Med 2006; 355: 241-250.

22. Chang YC, Chang TJ, Jiang YD, Kuo SS, Lee KC, Chiu $\mathrm{KC}$, et al. Association study of the genetic polymorphisms of the transcription factor 7-like 2 (TCF7L2) gene and type 2 diabetes in the Chinese population. Diabetes 2007; 56: 2631-2637. 